\title{
Preliminary mineralogical study of the flotation sand from the Tăuşani tailing pound (Moldova Nouă, Romania)
}

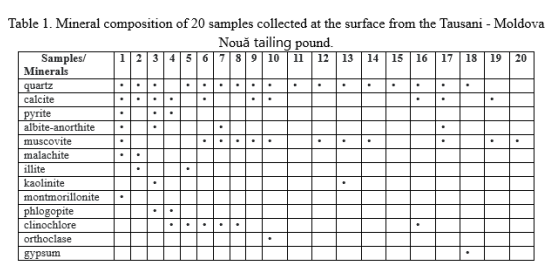

\section{DELIA-GEORGETA DUMITRAS ${ }^{1}$, STEFAN H MARINCEA $^{2}$, STEFAN MARINCEA ${ }^{1}$ AND ANTONELA NEACSU $^{3}$}

${ }^{1}$ Geological Institute of Romania

${ }^{2}$ The Institute for Advanced Studies in Levant Culture and Civilization

${ }^{3}$ University of Bucharest

Presenting Author: d_deliaro@yahoo.com

The Tăuşani tailing pound contains waste material resulting from the flotation of the porphyry cooper deposit from Suvorov Moldova Nouă, hosted by granodiorites of Upper Cretaceous age and contact rocks (skarns, hornfels). The tailing, classified as a dangerous industrial waste, is of "plain" type, has an area of 165.85 ha and a volume of 7.7 million cubic meters. It is located on the left bank of the Danube, near Moldova Veche town. The purpose of this paper is to document the mineralogical composition of the tailing sands composing this huge waste. The skarns hosting the copper mineralization are composed of garnets \pm pyroxenes, vesuvianite and wollastonite, whereas the porphyry deposit is of high-sulfidation type. In the skarn area, the hydrothermal activity subsequent to the pyrometasomatic process led to the formation of epidote, chlorite, quartz, calcite, sulfides which formation parallels that of similar minerals in granodiorite. At the end of the hydrothermal activity, carbonates, anhydrite, zeolites were formed. The mineralization occurs as irregular bodies or along discordant cracks affecting the host rocks. Ore minerals consist in chalcopyrite, pyrite, magnetite, and minor molybdenite, sphalerite and tetrahedrite. The flotation sand from the Tăuşani tailing pound contains mineral phases grouped into a light fraction (mainly quartz, calcite, feldspars and clay minerals), and a heavy fraction, consisting of pyrite. The sand is unconsolidated, with grains generally smaller than $0.4 \mathrm{~mm}$; the main fraction are found on the $0.2 \mathrm{~mm}$ sieve and consists of clay minerals, quartz, gypsum, minor anhydrite and calcite. Feldspars and quartz generally appear on the larger sieves. Table 1 shows the mineral composition of 20 samples collected from the surface of the tailing pound, as determined by X-ray powder diffraction. The minor elements identified by atomic absorption spectrometry in the deposit are: tin, nickel, cobalt, germanium, gallium, tellurium, selenium, bismuth, cadmium and indium. Pyrite is Asbearing. The pollution with dust particles carried by the wind is important and also affects the Serbian (right) bank of the Danube. The solution for the local stabilization of the flotation sand consisted in the installation of a water-aspersion system for wetting the dust. 